PUBLIC AFFAIRS

\section{A Debate beyond Sexuality}

\section{"Tradition," Human Rights and Uganda's Gay Death Penalty}

Kristen Cheney

U DAYTON

In the fall of 2009, MP David Bahati introduced a bill to Uganda's Parliament proposing tighter strictures on expressions of homosexuality, which were already outlawed in Uganda by the 1950 penal code and 1995 Constitution. The Anti-Homosexuality Bill quickly gained attention in the US media, whose own "culture wars" have been raging over the question of same-sex marriage. Most notable in the bill was the provision that gay Ugandans could actually be put to death for "aggravated homosexuality"-meaning committing same-sex acts with a minor, family member or disabled person-or where the "aggressor" is HIV-positive. Further, the bill would make it obligatory for people who "discover" another's homosexuality to inform on them. Those who failed to do so would face jail time.

The media have made much of US evangelical influence on Uganda's civic and political leaders, citing incidents like Defend the Family's Scott Lively speaking at a 2009 three-day "Seminar on Exposing the Homosexual Agenda" in Kampala as the inspiration for this bill. Ugandan leaders have taken offense at suggestions that they've caved to missionary neocolonialism. Instead, many regard homosexuality as the latest insidious Western colonial imposition that must be resisted. I suggest that there is much more at work here than a debate about cultural values, or even sexuality. Central to this issue are questions of reproduction, tradition and human rights.

The perceived threat in Uganda isn't homosexuality alone, and Bahati's bill is not just a result of the anti-homosexual fervor whipped up by American neoconservative evangelicals. As Marc Epprecht discussed in Heterosexual
Africa? (2008), there's a long history of denial of African homosexuality. I argue that one could view the debate as a moral panic connected to the overwhelming concern with fertility in Ugandan society. Herdt et al (Moral Panics, Sex Panics 2009) have pointed out that sexual issues are often at the center of moral panics, but that they tend to reflect wider concerns with societal change. With the second highest fertility rate in the world, Ugandans take fertility seriously, often using it as a barometer of national security. Many countries view a steady birth

\section{[S] exual issues are often at the}

\section{center of moral panics, but}

\section{... they tend to reflect wider}

\section{concerns with societal change.}

rate as a sign that the future will be secured through both sexual and social reproduction, but Uganda has taken this concern to another level: a woman interviewed by the BBC in December 2009 fretted, "How will society get children if men start marrying men?" (Joshua Mmali, "Uganda Fear over Gay Death-Penalty Plans"). MP Margaret Muhanga wrote in an October 26, 2009 New Vision editorial, "If all of us were to become gay, where would the next generation come from? [...] Remember these homosexuals cannot reproduce. They must recruit, and they want our children."

The bill's ostensible intention is to "protect the traditional family," when in fact Ugandans have always had very pliable family arrangements that involve, among other things, widespread informal child fosterage, polygamy (formal and informal), and extensive labor migration. Uganda is clearly still experiencing growing pains as it struggles with internal structural issues in a rapidly globalizing nation, but tradition is reified in the language of the bill in such a way that "the traditional family" is seen merely and statically as "heterosexual" and even nuclear, belying the multiple family formations that continue to characterize Ugandan social and sexual reproduction.

What is perhaps most unfortunate about the development of this bill is the way in which it regresses from adherence to a universal human rights standard. Uganda's 1995 Constitution was very progressive in its recognition of the rights of every citizen, including specific provisions for historically marginalized groups like women, children and the disabled. However, Bahati was quoted by the BBC's Focus on Africa program as saying, "Homosexuality it is not a human right..." and Ethics and Integrity Minister James Buturo took it one step further. "Homosexuals can forget about human rights," he said flatly to the media, thus paving the way for further human rights abuses against any other minorities.

After much international outcry, a Parliamentary review committee tabled the bill in May 2010, claiming that it was weak and redundant to existing laws (see Rodney Muhumuza's "Cabinet Committee Rejects Bahati Bill" in the Daily Monitor). But debate over homosexuality-and violence against LBGTQ people-continues. The irony is that the international attention the bill has garnered may ultimately help bolster the Ugandan gay rights movement. If the homosexuality debate does indeed reflect concerns about fertility, Ugandans need not worry: allowing gays and lesbians to live and love openly won't challenge Uganda's standing. If the issue is about the social reproduction of "traditional" values, I sincerely hope Ugandans will choose human rights over neoconservativism.

Kristen Cheney is assistant professor of anthropology at the University of Dayton and has been conducting research in Uganda since 1993. She is author of Pillars of the Nation: Child Citizens and Ugandan National Development (2007) and is currently preparing a manuscript on African orphanhood in the age of HIV and AIDS. $\mathrm{W}$

\title{
Climate Change and Human Rights in Bangladesh
}

\section{SIDDIQUR RAHMAN}

JAHANGIRNAGAR U

Throughout the world, environmental degradation and climate change are major contemporary concerns. It is ironic that Bangladesh is going to be one of the worst victims of climate change, as it is one of the countries least responsible for this change. Bangladesh's greenhouse gas emis- sions rate is one of the lowest in the world, both in the aggregate and in per capita terms. The per capita emission of $\mathrm{CO}_{2}$ in Bangladesh is a mere 0.2 tons, compared with an average of six tons

cally exposed to a multitude of adverse impacts of climate change, a problem compounded by the country's low adaptive capacity (due to its extreme poverty).

\section{HUMAN RIGHTS FORUM}

in the industrial world. However, because of its location in the tropics, Bangladesh is geographi-
The livelihood of most of the people in Bangladesh is agriculture-related. Climate 